\title{
Impact analysis of critical success factors on the benefits from statistical process control implementation
}

\author{
Fabiano Rodrigues Soriano ${ }^{\mathrm{a} *}$, Pedro Carlos Oprime ${ }^{\mathrm{b}}$, Fabiane Letícia Lizarelli ${ }^{\mathrm{b}}$ \\ aniversidade Federal de São Carlos, São Carlos, SP, Brasil \\ bUniversidade Estadual de Santa Cruz, llhéus, BA, Brasil \\ *frsoriano@uesc.br
}

\begin{abstract}
The Statistical Process Control - SPC is a set of statistical techniques focused on process control, monitoring and analyzing variation causes in the quality characteristics and/or in the parameters used to control and process improvements. Implementing SPC in organizations is a complex task. The reasons for its failure are related to organizational or social factors such as lack of top management commitment and little understanding about its potential benefits. Other aspects concern technical factors such as lack of training on and understanding about the statistical techniques. The main aim of the present article is to understand the interrelations between conditioning factors associated with top management commitment (Support), SPC Training and Application, as well as to understand the relationships between these factors and the benefits associated with the implementation of the program. The Partial Least Squares Structural Equation Modeling (PLS-SEM) was used in the analysis since the main goal is to establish the causal relations. A cross-section survey was used as research method to collect information of samples from Brazilian auto-parts companies, which were selected according to guides from the auto-parts industry associations. A total of 170 companies were contacted by e-mail and by phone in order to be invited to participate in the survey. However, just 93 industries agreed on participating, and only 43 answered the questionnaire. The results showed that the senior management support considerably affects the way companies develop their training programs. In turn, these trainings affect the way companies apply the techniques. Thus, it will reflect on the benefits gotten from implementing the program. It was observed that the managerial and technical aspects are closely connected to each other and that they are represented by the ratio between top management and training support. The technical aspects observed through SPC application directly affect the benefits from the program.
\end{abstract}

Keywords

Quality control. Quality improvement. SPC. Structural Equations Model.

How to cite this article: Soriano, F. R., Oprime, P. C., \& Lizarelli, F. L. (2017). Impact analysis of critical success factors on the benefits from statistical process control implementation. Production, 27 , e20162040. http://dx.doi.org/10.1590/0103-6513.204016

\section{Introduction}

The Statistical Process Control - SPC is a set of statistical techniques focused on process control, monitoring and analyzing the variation causes in the quality characteristics and/or in the process parameters. Several authors see SPC not only as a collection of techniques, but also as a concept able to define the criteria to interpret variabilities and their causes (Antony \& Taner, 2003; Burr, 1976; Caulcutt, 1996; Hayes \& Romig, 1977; Oakland, 2008; Woodall, 2000).

The use of SPC, specifically of the control chart, is based on statistical methods. It aims at stabilizing the process by identifying and acting on the two types of variation causes. Special causes are few, but identifiable and they have strong effect on variability and product quality. There are many common causes, but they have little effect on process variability (Montgomery, 2010; Montgomery, 2014; Oakland, 2008; Woodall \& Montgomery, 1999). 
The SPC is a widespread technique, mainly in the automobile sector, which uses it as control and process improvement tool (Montgomery, 2010; Woodall \& Montgomery, 1999; Woodall, 2000). Its use has expanded in the automotive sector in the XXI century due to the diffusion of many improvement programs such as Six Sigma, TPM (Total Productive Maintenance) and TQM (Total Quality Management). These programs have incorporated the monitoring and statistical control process philosophy to their principles. However, it is still difficult to implement, do the maintenance and keep SPC running in the organizations (Antony et al., 2000; Does et al., 1997; Elg et al., 2008; Montgomery, 2010).

Two main action types should be developed in order to apply SPC: the local action, which is conducted by line operators who must monitor the process and restore the status quo; and the systemic action, which is conducted by the top management. The systemic action requires investments and efforts to change the system maintenance culture, but such change enables mid- and long-term impact on the results (Elg et al., 2008; Mason \& Antony, 2000). Therefore, it is reasonable inferring that the SPC implementation involves actions in the strategic, tactical and operational levels (Hoerl \& Snee, 2010).

Implementing SPC in organizations is a complex task. The main reasons for its failure are related to organizational, managerial, cultural and social factors, such as lack of top management commitment and support. Other reasons are associated with technical factors such as lack of training in statistical techniques and in their inappropriate application, as well as little understanding about the control chart and the statistical tools (Antony et al., 2000; Does et al., 1997; Judi et al., 2009; Mason \& Antony, 2000). More research on the herein discussed topic is necessary due to the importance of factors successfully affecting SPC implementation and to the lack of studies about the influence of these factors on its implementation in the Brazilian industries of the auto-parts sector.

The aim of the present paper is to identify the Critical Success Factors (CSF) through a Systematic Literature Review (SLR) in order to set a successful SPC and to prepare a field survey instrument able to capture the perceptions of SPC users from the Brazilian auto-parts industries about these factors and about the results associated with the program. Antony et al. (2000) have defined the CSF as the essential points to be achieved or the main areas responsible for producing competitive advantages. The CSF listed in the present article are: actions, tactics, methods, tools and techniques that contribute to SPC success.

The main aim of the current study is to understand the interrelations between conditioning factors associated with top management commitment (Support), SPC and statistical tools (Training) knowledge, and with SPC use (Application), as well as the factors associated with the relationships between these factors and the benefits coming from the implementation of the program. The Partial Least Squares Structural Equation Modeling (PLS-SEM) was used in the analysis, since the goal is to set the causal relationships.

The present paper was divided in six sections. The introduction presents the subject and the research problems. It is followed by the second section, which shows a literature review on CSF for SPC implementation. The third section presents the research method, and section four analyzes the results and discusses the main findings. The fifth section presents the limitations of the present study. The article ends in the conclusion.

\section{Literature review}

\subsection{Identifying CSF for SPC implementation}

There are complex and numerous factors affecting the SPC implementation. These factors are prerequisites for the creation of an environment favorable for the SPC use. The CSF conduction failure may lead to issues associated with the implementation, maintenance and continuity of the program (Antony et al., 2000; Lim et al., 2014; Rohani et al., 2010; Woodall \& Montgomery, 1999).

There are two important aspects associated with SPC implementation: the managerial aspect, also called organizational; and the technical or operational aspects (Does et al., 1997; Mason \& Antony, 2000; Elg et al., 2008; Putri \& Yusof, 2008; Rohani et al., 2009; Rohani et al., 2010; Xie \& Goh, 1999). These two aspects of SPC implementation were taken into consideration in the analysis conducted in the current study. The CSF can be classified as a managerial or technical factor, and it enables analyzing these two aspects.

The technical impairments prevent the application of statistical concepts and tools. The greatest challenge is to eliminate the barriers people face when they deal with such tools. This goal can be achieved through continuous SPC training (Elg et al., 2008; Lim et al., 2014; Mason \& Antony, 2000). From an organizational viewpoint, it is quite difficult to have the whole organization committed with the program, but such commitment is accomplished through top management support (Elg et al., 2008; Lim et al., 2014). 
Many studies (Fryer et al., 2007; Lee, 2004; Marin-Garcia at al., 2008) have focused on identifying CSF through Continuous Improvement $(\mathrm{Cl})$ activities. The authors also emphasize the importance of management aspects such as senior management support and of technical aspects, such as training for $\mathrm{Cl}$ implementation and maintenance. Despite the fact that SPC is considered a Cl form (Mason \& Antony, 2000; Grigg \& Walls, 2007b), few studies have analyzed the CSF related to SPC use in Brazilian companies.

A Systematic Literature Review (SLR) was conducted to define the procedures in order to impartially identify, analyze and interpret the available evidences related to a particular topic, research question or phenomenon of interest, which can be replicable and evidence-based to create generalizations (Biolchini et al., 2007; Brereton et al., 2007; Tranfield et al., 2003). The following search string was adopted to identify critical factors in the literature: "statistical process control" or "SPC" or "control chart", and "critical success factors" or "success factors".

The search string was applied to four relevant databases to the research: Web of Science, Scopus, Engineering Village and Google Scholar. After reading the titles and abstracts, 39 relevant articles were identified, and another 10 papers found through cross-reference were added to the corpus. At the end, there was information from 20 journal and conference papers and 43 CSF. Compilations of the main factors and authors are seen in Table 1. The most cited CSFs in the literature (80\% of the 173 citations about CSF) are shown in Table 1.

Table 1. Key Critical Success Factors in SPC implementation.

\begin{tabular}{|c|c|c|c|c|c|c|c|c|c|c|c|c|c|c|c|c|c|c|c|c|}
\hline Critical Success Factors & 1 & 2 & 3 & 4 & 5 & 6 & 7 & 8 & 9 & 10 & 11 & 12 & 13 & 14 & 15 & 16 & 17 & 18 & 19 & 20 \\
\hline $\begin{array}{l}\text { 1. Top management support/ } \\
\text { commitment/actions }\end{array}$ & $x$ & $x$ & $x$ & $x$ & & $x$ & $x$ & $x$ & & $x$ & $\mathrm{x}$ & $x$ & $x$ & $x$ & $x$ & $x$ & $\mathrm{x}$ & $x$ & $\mathrm{x}$ & $\mathrm{X}$ \\
\hline 2. Training and education in SPC & $x$ & & $x$ & $x$ & $x$ & $x$ & $x$ & $x$ & & $\mathrm{x}$ & $x$ & $\mathrm{x}$ & $x$ & $x$ & $x$ & $x$ & $\mathrm{x}$ & $x$ & $x$ & $x$ \\
\hline 3. Teamwork / team SPC & & $\mathrm{X}$ & $x$ & $x$ & $x$ & $x$ & $x$ & & & & $x$ & $x$ & $x$ & $x$ & $\mathrm{x}$ & $x$ & $\mathrm{x}$ & & $\mathrm{x}$ & \\
\hline $\begin{array}{l}\text { 4. Properly control chart construction } \\
\text { based on valid assumptions }\end{array}$ & & $x$ & $x$ & & $x$ & $x$ & $x$ & $x$ & & $\mathrm{x}$ & $x$ & $\mathrm{x}$ & & $x$ & & $x$ & $\mathrm{x}$ & $x$ & & \\
\hline 5. Adequate measurement system & & $x$ & $x$ & & & $x$ & $x$ & $x$ & $x$ & $x$ & $x$ & & & & $x$ & $x$ & $\mathrm{x}$ & $x$ & $x$ & \\
\hline $\begin{array}{l}\text { 6. Identification and measurement of } \\
\text { critical quality characteristics }\end{array}$ & & $x$ & $x$ & & & $x$ & $x$ & $x$ & & $x$ & $x$ & $\mathrm{x}$ & & & $\mathrm{x}$ & $x$ & $\mathrm{x}$ & $x$ & & \\
\hline 7. Cultural change & & & & $x$ & & $x$ & $x$ & & & & $x$ & & $x$ & $x$ & $x$ & $x$ & $x$ & & & $\mathrm{X}$ \\
\hline 8. Process definition and prioritization & & $x$ & & $\mathrm{x}$ & & $x$ & $x$ & & & & $x$ & $\mathrm{x}$ & & & $\mathrm{x}$ & $x$ & $\mathrm{x}$ & & & \\
\hline 9. Use of the SPC software system & & & & $x$ & & $\mathrm{x}$ & $x$ & & & $\mathrm{x}$ & $x$ & & & & & $x$ & $\mathrm{x}$ & & & \\
\hline 10. Adoption of a pilot study & & $\mathrm{X}$ & & & & $x$ & $x$ & & & & $x$ & & & & $x$ & $x$ & & & $x$ & \\
\hline 11. Use of a SPC facilitator & & & $\mathrm{x}$ & & & & $x$ & & & & $\mathrm{x}$ & & & & $\mathrm{x}$ & $\mathrm{x}$ & $\mathrm{x}$ & & & \\
\hline 12. Empowerment & $x$ & & $x$ & & $x$ & & & & & & & & $x$ & $x$ & & & & & & \\
\hline $\begin{array}{l}\text { 13. Documentation and process } \\
\text { knowledge updates }\end{array}$ & & & $x$ & & & & $x$ & & & & $x$ & & & & & $x$ & & & & \\
\hline
\end{tabular}

14. Properly interpreted and handled control chart

$\mathrm{x} \quad \mathrm{x}$

(1) Gordon et al. (1994), (2) Does et al. (1997), (3) Rungtusanatham et al. (1999), (4) Xie \& Goh (1999), (5) Mason \& Antony (2000), (6) Antony et al. (2000), (7) Rungasamy et al. (2002), (8) Antony \& Taner (2003), (9) Grigg \& Walls (2007a), (10) Grigg \& Walls (2007b), (11) Chen et al. (2008), (12) Elg et al. (2008), (13) Putri \& Yusof (2008), (14) Phyanthamilkumaran \& Fernando (2008), (15) Rohani et al. (2009), (16) Rohani et al. (2010), (17) Mahanti \& Evans (2012), (18) Rantamaki et al. (2013), (19) Sharma \& Kharub (2014), (20) Lim et al. (2014).

After being identified, the CSFs (Table 1) were divided in technical and managerial aspects for SPC implementation. The top management support/commitment/actions (factor 1) were appointed as managerial factor (Antony et al., 2000; Does et al., 1997; Elg et al., 2008). Training and education in SPC (factor 2), properly control chart construction based on valid assumptions (factor 4), adequate measurement system (factor 5), identification and measurement of critical quality characteristics (factor 6) and properly interpreted and handled control chart (factor 14) were pointed out as CSFs related to technical impairments (Antony et al., 2000; Does et al., 1997; Mason \& Antony, 2000). The other factors (3, 7, 8, 9, 10, 11, 12 and 13) were not taken into consideration in the present study, because they were less associated with the managerial and technical aspects. The selected CSF were subdivided in the following constructs of the present research: Support, Training and Application.

\subsection{Formulating the research hypotheses}

According to the literature, the construction of an environment focused on an improvement culture is an important aspect for SPC deployment. It is worth focusing on customer satisfaction, on mutual trust among peers and on the improved visibility of problems within the scope of organizations that understand SPC as a necessary technique to keep stable processes (Grigg \& Walls, 2007a). Top management support and resources 
are the basic conditions to create an improvement culture (Antony \& Taner, 2003; Mahanti \& Evans, 2012). Top management commitment is one of the most important factors for a successful SPC implementation (Mahanti \& Evans, 2012; Rungasamy et al., 2002).

Senior executives should assist initiatives supporting time, financial and human resources (Antony \& Taner, 2003; Mahanti \& Evans, 2012; Mason \& Antony, 2000). The senior management support and training initiatives to generate and spread SPC knowledge are related to each other. The SPC should start in the top management level and then be spread to other organizational levels through trainings supported by the senior management (Grigg \& Walls, 2007a). Senior management is responsible for making resources available for the training sessions, as well as for encouraging employees to participate in them (Mahanti \& Evans, 2012; Phyanthamilkumaran $\&$ Fernando, 2008). Based on these theoretical statements, the current paper aims to confirm the following research hypothesis.

\section{$\mathrm{H}_{1}$ : Top management commitment positively affects training and education in SPC}

The resistance to SPC adoption at different organizational levels is one of the main challenges faced throughout the implementation program. One of the reasons for such resistance results from the lack of statistical knowledge; however, this gap can be fulfilled with top management support (Grigg \& Walls, 2007b; Lim et al., 2014). However, it demands time to employees to dedicate to SPC and to make the appropriate decisions to apply the control charts; to observe the technical aspects, such as the statistical assumptions used at the time to generate the chart; to identify the critical characteristics during the application of the statistical control charts; and to analyze and remove the special causes. Such time demand requires top management support to be fulfilled (Lim \& Antony, 2013; Mahanti \& Evans, 2012; Sharma \& Kharub, 2014). Therefore, the present study aims at confirming the following research hypothesis:

\section{$\mathrm{H}_{2}$ : Top management commitment positively affects SPC application and use}

The control chart application is based on proper statistical assumption domains and on the correct selection of control charts (Antony \& Taner, 2003; Rungasamy et al., 2002), which may enable process adjustments, whenever necessary (Mason \& Antony, 2000). The control charts should be applied to the critical characteristics as functional and safety features of products and processes (Antony \& Taner, 2003). Training is responsible for the possibility of properly applying the control charts and the statistical tools, and it regards the correct choice for charts and critical characteristic (Mahanti \& Evans, 2012; Phyanthamilkumaran \& Fernando, 2008; Rohani et al., 2010; Mahanti \& Evans, 2012). Knowledge is a conditioning factor for the appropriate choice for control charts and for their application, which requires training and education (Mahanti \& Evans, 2012; Putri \& Yusof, 2008). Based on the aforementioned, the third research hypothesis to be confirmed was formulated.

According to Yamamoto \& Bellgran (2013), infrastructural investments in the organization regard not only the physical assets, but also organizational procedures and intangible assets such as knowledge, skill, motivation and leadership. The SPC training should present different control chart types and the situations that each chart should be applied, as well as how to identify special causes, to collect and record data in the control chart (Antony \& Taner, 2003; Rohani et al., 2010); the presence of these issues concern a quality training. Other important issues associated with quality training are related when the acquired knowledge about SPC is applied after the training session. and when there is additional training in SPC application and tools (it features new control chart techniques and recalls the fundamental concepts of conducting the enforcement activities of control charts) (Mahanti \& Evans, 2012).

$\mathrm{H}_{3}$ : The statistical training increases the technical understanding about SPC, and consequently, it positively affects SPC application and use

It is consensus among many authors that one of the benefits from SPC is the process variation reduction to achieve the best quality performance of processes/products (Antony et al., 2000; Antony \& Taner, 2003; Grigg \& Walls, 2007a; Hoerl \& Snee, 2010; Lim et al., 2014; Lim \& Antony, 2013). However, such demands rapidly identify and act on the special variation causes (Mason \& Antony, 2000).

There is the paradigm that using control charts allows process behavior prediction since there is knowledge accumulation and the systematic use of statistical methods to reduce future uncertainties able to cause a paralyzing behavior with time (Lim \& Antony, 2013). Other benefits reported in the literature are: significant reduction in the time spent to solve quality issues aiming at reducing scrap, rework and inspection (Antony et al., 2000; Lim \& Antony, 2013; Mason \& Antony, 2000); fact that leads to cost reduction (Grigg \& Walls, 2007a, b; Mason \& Antony, 2000).

The identification of critical quality characteristics of control chart applications (Rungasamy et al., 2002; Antony \& Taner, 2003), of proper charts interpretation and of taking the necessary actions when special variation 
causes are presented are important factors for SPC implementation and for its results (Mason \& Antony, 2000). More statistical issues such as sampling frequency, sub-group size and limit calculations are essential for making the correct interpretations and for the routing actions (Antony \& Taner, 2003). According to the literature and from a technical perspective, the choice and correct use of control charts are important factors for achieving positive results from the SPC use in the organizations (Antony et al., 2000; Mahanti \& Evans, 2012). The effective application of control charts is directly related to the benefits generated by the SPC program (Mahanti \& Evans, 2012; Phyanthamilkumaran \& Fernando, 2008; Putri \& Yusof, 2008; Rohani et al., 2010). Thus, the fourth hypothesis was established according to SPC application concepts.

H4:The correct application of control charts positively affects the benefits generated by the program

A model was established to analyze the relationships between CSF and the benefits generated by the program (Figure 1). The aim is to analyze whether there are positive relationships between the three independent constructs (Support, Training and Application) and the dependent construct (Benefits), as well as to analyze the relationships between the independent constructs, which derive from the existing interaction between the Support and Training, Support and Application and Training and Application.

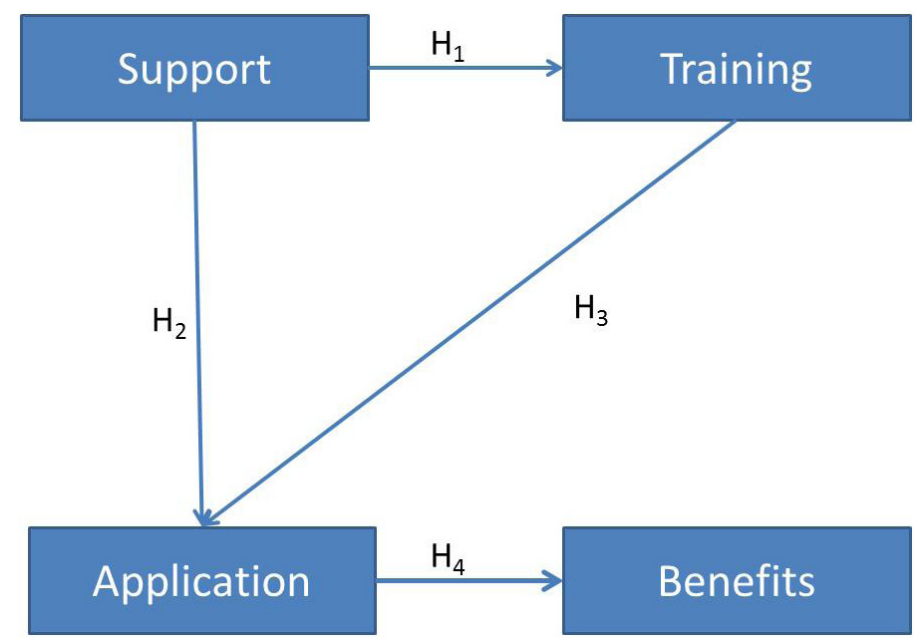

Figure 1. Research model.

\subsection{Identifying the research variables}

The managerial and technical aspects are of great importance to SPC implementation. A SLR about CSF was conducted to identify the important factors related to these aspects. These CSFs were divided in three constructs. One of these constructs was directly related to the managerial aspect (Support). Because there was a large number of CSFs related to the technical aspect, it was split in two constructs, namely: Training and Application.

The variables of each construct are shown in Table 2. These variables derive from CSF-associated concepts and are divided according to the model of the constructs: Support (managerial aspect), Training and Application (technical aspect), Benefits (results). The CSFs for SPC in the present study are shown in Table 1; just the CSF associated with the technical and managerial aspects were herein taken into account. Thus, the following factors were included in the study: i) top management support/commitment/action (Factor 1 in Table 1 - Support construct); ii) SPC training and education (Factor 2 - Training construct); iii) properly control chart construction based on valid assumptions (Factor 4 - Application construct); iv) adequate measurement system (Factor 5 - Application construct); v) identification and measurement of critical quality characteristics (Factor 6 - Application construct); and vi) properly interpreted and handled control chart (Factor 14 - Application construct). The other factors shown in Table 1 were not included in the current survey because they were less representative of the aspects chosen for the present article. 
Table 2. Constructs and variables.

\begin{tabular}{|c|c|c|c|}
\hline Constructs & Variables & Concepts & Authors' Concept \\
\hline \multirow{3}{*}{ Support } & $\begin{array}{l}\text { VCA1 - Top management } \\
\text { regularly leads the quality of } \\
\text { improvement efforts (factor } 1 \text { ) }\end{array}$ & $\begin{array}{l}\text { Top management should enable and emphasize } \\
\text { the continuous improvement culture, value the } \\
\text { gains incrementally and steadily made }\end{array}$ & $\begin{array}{l}\text { Antony et al. (2000), Grigg \& Walls (2007a), } \\
\text { Hayes \& Romig (1977), Hoerl \& Snee (2010), } \\
\text { Laohavichien et al. (2011), Lim \& Antony } \\
\text { (2013), Mahanti \& Evans (2012), Montgomery } \\
\text { (2014), Oakland (2008), Phyanthamilkumaran \& } \\
\text { Fernando (2008). }\end{array}$ \\
\hline & $\begin{array}{l}\text { VCA2- Top management } \\
\text { provides adequate resources } \\
\text { to promote SPC (factor } 1 \text { ) }\end{array}$ & $\begin{array}{l}\text { Providing the necessary resources such as } \\
\text { training and providing incentives for SPC use }\end{array}$ & $\begin{array}{l}\text { Antony et al. (2000), Antony \& Taner (2003), } \\
\text { Grigg \& Walls (2007a), Hoerl \& Snee (2010), } \\
\text { Laohavichien et al. (2011), Mahanti \& Evans } \\
\text { (2012), Mason \& Antony (2000), Sharma \& } \\
\text { Kharub (2014). }\end{array}$ \\
\hline & $\begin{array}{l}\text { VCA3- Top management } \\
\text { provides structure support for } \\
\text { SPC (factor 1) }\end{array}$ & $\begin{array}{l}\text { Support available for SPC implementation such } \\
\text { as expert advice, training, dedication hours of } \\
\text { employees and specific software license }\end{array}$ & $\begin{array}{l}\text { Ahmed et al. (2012), Bhote (1987), Lim \& } \\
\text { Antony (2013), Mahanti \& Evans (2012), } \\
\text { Rohani et al. (2010), Sharma \& Kharub (2014). }\end{array}$ \\
\hline \multirow{4}{*}{ Training } & $\begin{array}{l}\text { VT1- The SPC training is } \\
\text { given to workers involved in } \\
\text { the manufacture and in SPC } \\
\text { (factor 2) }\end{array}$ & $\begin{array}{l}\text { It is important that the training program } \\
\text { include operators. The training should address } \\
\text { the identification of special causes, of correct } \\
\text { control chart types, data collection and control } \\
\text { chart filling }\end{array}$ & $\begin{array}{l}\text { Antony \& Taner (2003), Caulcutt (1996), } \\
\text { Rohani et al. (2010). }\end{array}$ \\
\hline & $\begin{array}{l}\text { VT2- The knowledge } \\
\text { acquired about SPC is applied } \\
\text { immediately after training } \\
\text { (factor 2) }\end{array}$ & $\begin{array}{l}\text { The acquired SPC knowledge in training should } \\
\text { be applied immediately after training in order } \\
\text { to avoid significant concept losses }\end{array}$ & $\begin{array}{l}\text { Ahmed et al. (2012), Bhote (1987), Lim \& } \\
\text { Antony (2013), Mahanti \& Evans (2012), } \\
\text { Rohani et al. (2010), Sharma \& Kharub (2014). }\end{array}$ \\
\hline & $\begin{array}{l}\text { VT3- Additional training in } \\
\text { SPC application and tools } \\
\text { is regularly accomplished } \\
\text { (factor } 2 \text { ) }\end{array}$ & $\begin{array}{l}\text { There should be trainings to feature the new } \\
\text { control chart techniques and to recall the main } \\
\text { concepts to achieve the enforcement activities } \\
\text { of control charts }\end{array}$ & $\begin{array}{l}\text { Antony et al. (2000), Hayes \& Romig (1977), } \\
\text { Mahanti \& Evans (2012), Rohani et al. (2010). }\end{array}$ \\
\hline & $\begin{array}{l}\text { VA1- Appropriate control } \\
\text { charts are used to monitor } \\
\text { process stability (factor 4) }\end{array}$ & $\begin{array}{l}\text { Appropriate control charts should be used; } \\
\text { chart type must be set, as well as the } \\
\text { parameters to be controlled according to the } \\
\text { features about to be scrutinized }\end{array}$ & $\begin{array}{l}\text { Antony et al. (2000), Grigg \& Walls (2007b), } \\
\text { Hoerl \& Snee (2010), Montgomery (2014), } \\
\text { Rohani et al. (2010). }\end{array}$ \\
\hline
\end{tabular}

\section{VA2- The Statistical} assumptions are observed (sample size, normality and adequate measurement system) through the use of

Application control charts (factor 5)

VA3- The SPC is applied to critical, functional and safety characteristics of products and processes (factor 6)

VA4- Special causes are identified and removed when the process is out of control (factor 14)

VR1 - The SPC substantially increases customer satisfaction

VR2- The SPC enhances the ability to analyze and solve problems

Benefits VR3- The SPC helps reducing process variations

VR4- The SPC use contributes to defect reduction and productivity gain
People involved with SPC have adequate command of statistical methods that enable control chart operations

Control charts should be applied to critical, functional and safety characteristics of products and processes

In case the process is out of control, the mechanisms that enable the operator to make adjustments whenever necessary should be adopted in order to bring the process back to stability

The consequences from customer satisfaction are more reliability on products, which positively affects the perception about the quality characteristics of products by customers The SPC helps identifying and solving problems when it is applied according to a continuous improvement approach

The SPC allows displaying process variability and improving actions to reduce variability and to decrease special causes

The SPC provides improved conformation quality and product defect reduction in the field, as well as improves business productivity by reducing mistakes during manufacturing and production line shutdowns
Ahmed et al. (2012), Bhote (1987), Lim \& Antony (2013), Mahanti \& Evans (2012), Sharma \& Kharub (2014).

Antony et al. (2000), Grigg \& Walls (2007a, b)

Hoerl \& Snee (2010), Mahanti \& Evans (2012),

Montgomery (2014), Rohani et al. (2010),

Sharma \& Kharub (2014).

Ahmed et al. (2012), Bhote (1987), Lim \& Antony (2013), Mahanti \& Evans (2012),

Sharma \& Kharub (2014).

Antony et al. (2000), Grigg \& Walls (2007a), Putri \& Yusof (2008), Rohani et al. (2009, 2010).

Caulcutt (1996), Mason \& Antony (2000). Antony et al. (2000), Antony \& Taner (2003), Grigg \& Walls (2007a, b), Hoerl \& Snee (2010), Lim et al. (2014), Mason \& Antony (2000).

Antony et al. (2000), Antony \& Taner (2003), Grigg \& Walls (2007a), Hoerl \& Snee (2010), Lim et al. (2014), Mason \& Antony (2000). 
Table 2 also shows the concepts related to the constructs and presents the authors who point out their importance. The concepts were turned into research variables associated with CSF. Each variable in Table 2 has a classification acronym based on the related construct, the factor it is related to is shown in parenthesis. The variables are applied to measure respondents' perception about how they are practicing these concepts in the auto-parts industries in order to capture the correlation between constructs.

\section{Research method}

A cross-section survey was used as research method to collect information of samples from Brazilian companies of the auto-parts sector according to Forza (2002) recommendations. The companies were selected based on the auto industry's guide from the National Association of Automobile Manufacturers and from the Brazilian Association of the Auto-Parts Industry, which brings together the leading manufacturers of the Brazilian auto-parts industry.

The population of interest comprises the auto-parts companies that have production plants in Brazil. The number of companies is not possible to be quantified, as the automotive chain has several links. However, 341 auto-parts manufacturing companies were identified and listed in the associations related to the sector. These 341 companies sere considered the population of the present study. Researches tried to contact these 341 companies, but only 170 of them were, actually, reached by phone or e-mail, or presented the features required by the present study, for example, some of these were commercial offices. Only 93 out of the 170 potential respondents agreed on participating in the study. Unfortunately, as the study is based on individual perspectives, it is not possible to retrieve data, unless the respondent agrees on participating.

New telephone and e-mail contacts, with those who have agreed with the survey, were made as an attempt to improve the representativeness of the sample; however, only 43 participants (12.6\% of the population) finished answering the questionnaire. The respondents were responsible for the company's SPC, as well as experienced in carrying out SPC activities. The major interest of the present study lies on the opinion of those who have been responsible for SPC for at least three years in the auto-parts sector. The fact of not having access to all the population can produce bias in the estimation of statistical parameters and it is not possible to generalize the results. However, the present article is of exploratory nature and aims at identifying the relationships between constructs. The statistical theories assume that the measured values of each population feature is accurate, but accuracy is difficult to be obtained in a complex research field (Cochran, 1977).

The variables were identified through SLR and through the analysis of CSF. The concepts of these critical factors, which were pointed out by leading authors, were operationalized in the questionnaire through statements for the respondents. The answers were given through a 05-point-Likert scale ("Despicable-01", "Very unimportant-02", "Indifferent-03", "Important-04", and "Very Important-05"). Each construct was measured based on the respondent's experience in order to test the research hypotheses suggested by the conceptual model.

After the development of the survey instrument and due to the complexity of the field research, significant number of variables of different nature and large qualitative measurements, it was important carrying out a structured pre-test questionnaire. Such procedure was important to mitigate and dispel doubts. The SPC experts from two previously selected companies have validated an electronic version of the questionnaire. They have filled out the questionnaire in front of the researcher. The respondents have given their opinions on the design of the sentences during the pre-test; thus, the ambiguities and unnecessary matters were removed from it.

The data collection stage in primary sources took place after the pre-test questionnaire was completed. A key concern of the field sampling research is to minimize bias estimates of the statistical parameters of interest to the researchers. Therefore, it is critical to assure the accuracy of measurements applied to the research variables. There is also the need to drive a sampling process based on random statistical assumptions and on the unconditional independence between individuals belonging to the sample.

The revised version of the questionnaire was electronically sent to each company and the statistical validity of the questionnaire was verified through Cronbach's alpha in the 43 questionnaires. The data were tabulated in Microsoft Excel spreadsheet after the answers were obtained, and it enabled implementing the Statistica software to start data analysis.

The Cronbach's alpha showed that the application of the multivariate analysis was appropriate, because it indirectly shows the validity of the data collection instrument. Such analysis is important because problems may arise from data collection. These problems could affect the accuracy of the study, thus alpha is important to verify: i) whether the sample belongs to the population of interest; ii) whether the research instrument was properly filled out; iii) whether the variables were precisely measured (Cochran, 1977). The alpha Cronbach is used 
to assess whether the sample is free of bias and whether the answers - as a whole - are reliable in a PLS-SEM. It supports the reliability of the model and the internal consistency analysis (Hair et al., 2014).

\subsection{Procedure for data analysis - Partial Least Squares Structural Equation Modeling (PLS-SEM)}

The first part of the SEM analysis lies on developing a confirmatory factor analysis to validate the research variables. The application of the Confirmatory Factor Analysis allows assessing whether the variables are directly or indirectly related to the corresponding latent constructs (constructs that cannot be directly measured because they are subjective) (Hair et al., 2009; Jobson, 1992).

There are two steps to be followed in the confirmatory analysis. At first, it is worth finding the variables belonging to a specific construct that had high common variance degree, as well as congruence of high-factor loadings. In other words, this type of analysis checks whether the variables were related to the construct through the internal validity of the variables (Basilevsky, 1994). The second moment concerned the discriminant validity; it analyzed the ability of the constructs to be different from one another through external validity. Thus, there was the attempt to determine whether the latent constructs are different and to minimize the adverse effects on the analysis and on data interpretation (Hair et al, 2009; Jobson, 1992).

It was made the choice for using the PLS-SEM. The main reasons for making the option of using the PLS are basically the same in several studies, namely: small violations in data normality, formative measures, small sample size, and the last one is the most prevalent reason in recent years (Hair et al., 2012). The benefit from PLS-SEM is the ability to confirm the relationships between latent variables when they are found in the population, especially in situations when sample sizes are small (Hair et al., 2012). Thus, the PLS-SEM is useful in exploratory research and in estimating complex models (Hair et al., 2011, 2012). Despite the method consistency, it was assessed whether there were significant violations in the statistical assumptions (multivariate normality and multicollinearity); however, none has been violated.

Regarding the number of variables related to the latent constructs, the literature recommends that four variables are able to explain a construct (Hair et al., 2009). The selection of the number of variables depends on criteria such as freedom degrees, and variance and covariance matrix. Thus, there will be, at least in theory, enough information to identify a solution to the set of structural equations (Hair et al., 2009; Jobson, 1992). No more than four variables were selected to represent each construct, as shown in Table 2.

The model will be presented through a path diagram for a better understanding. It is necessary to build a model pointing out the one-way effect of one variable on another, as the PLS-SEM is a more exploratory than confirmatory model. The diagram indicates the relationship through the arrows to graphically show the relationships between variables. A visual representation of paths diagram helps clarifying the factor loadings, identifying the most significant variables of each construct by specifying the structural model (Hair et al., 2009).

The analysis was performed by estimating the paths, which consists of assessing the load factor regarded as optimal value $\geq 0.5$. Result loads higher than 0.7 are considered to be good. Variables with low loads, less than 0.3, should be excluded from the model after the confirmatory analysis (Hair et al., 2009).

\section{Result analysis}

\subsection{Confirmatory analysis}

In the previous section, all the procedures were presented and the importance of making the confirmatory analysis was showed. The confirmatory factor analysis was used to analyze the legitimacy and veracity of certain variables to build the study and remove less representative variables. The factor analysis, as proposed by Hair et al. (2009), was performed through statistical Chi square test, using the T-Student distribution. The suitability of a variable in a structural model was determined by the generated $p$-value. In view of the results obtained after running the model (Table 3), only one variable did not present significant correlation with the construct.

The Confirmatory Analysis has shown that the variable VA3* (The SPC is applied to critical, functional and safety characteristics of products and processes) belonging to the construct Application displays $p$-value $<0.05$. The minimum requirement for the variable infers the internal validity of the construct at $p$-value $\geq 0.05$; thus, it is a non-significant variable for the model. Accordingly, this variable did not explain its construct within the model and the variable had to be removed from the model for subsequent analysis.

The hypothesis test seen in Table 3 shows the first part of the data analysis. The following table shows the significance level of the variables selected according to the confirmatory data analysis. 
Table 3. Confirmatory Factor Analysis.

\begin{tabular}{cccccc}
\hline \multirow{3}{*}{ Construct } & Variables & Parameter Estimate & Standard Error & $\begin{array}{c}\text { Factorial Weight } \\
\text { T Statistic }\end{array}$ & p-value \\
& VCA1 & 0.591 & 0.138 & 4.270 & 0.000 \\
Support & VCA2 & 0.411 & 0.113 & 3.654 & 0.000 \\
& VCA3 & 0.440 & 0.129 & 3.422 & 0.001 \\
\hline \multirow{3}{*}{ Training } & VT1 & 0.455 & 0.160 & 2.845 & 0.004 \\
& VT2 & 0.392 & 0.140 & 2.802 & 0.005 \\
& VT3 & 0.252 & 0.114 & 2.210 & 0.027 \\
\hline \multirow{3}{*}{ Application } & VA1 & 0.510 & 0.099 & 5.159 & 0.000 \\
& VA4 & 0.328 & 0.105 & 3.110 & 0.002 \\
& *VA3 & 0.223 & 0.154 & 1.446 & 0.148 \\
VA2 & 0.364 & 0.092 & 3.952 & 0.000 \\
\hline Benefits & VR1 & 0.570 & 0.127 & 2.501 & 0.000 \\
& VR2 & 0.282 & 0.098 & 3.015 & 0.004 \\
& VR3 & 0.411 & 0.136 & 2.629 & 0.003 \\
\hline
\end{tabular}

${ }^{*} \mathrm{p}$-value $>0.05$. This variable had to be removed from the model for subsequent analysis.

\subsection{Interpretation and propositions}

The next step after the internal validation was to validate the research hypotheses. The validation initiated with the Alpha Cronbach analysis, which aimed at analyzing the reliability of the model and its internal consistency (Hair et al., 2014). The alpha was calculated in each construct, and the elimination of variable VA3 was taken into account. The alpha value above 0.60 is considered suitable for exploratory research; thus, it can be considered a valid construct (Hair et al., 2009; Hair et al., 2014). Table 4 presents the validation results of the constructs.

Table 4. Cronbach's alpha test.

\begin{tabular}{cc}
\hline Constructs & Cronbach's alpha \\
\hline Support & 0.716 \\
Training & 0.603 \\
Application & 0.74 \\
Benefits & 0.668 \\
\hline
\end{tabular}

Regarding the PLS-SEM, the analysis of factor loadings was performed between the analyzed constructs and it enabled validating the hypotheses of the present study. Figure 2 shows the main results based on the proposed conceptual model. No violations were found in the model after the internal and external validity analysis.

The values in the arrows of Figure 2 refer to the factor loading results that were analyzed to validate the constructs: Support, Application, Training and Benefit. The path modeling method of PLS-SEM was chosen, as already stated, because it is considered more robust and less sensitive to sample size considerations and statistical assumptions such as the normality multivariate. Therefore, the literature recommends that loads $\leq 0.3$ are not representative and the variables should be removed from the model (Hair et al., 2014). Preferably, the factor loading value is $\geq 0.5$, and it indicates that the variable is representative of the model. There were no variables with factor loadings $\leq 0.3$ in the proposed model, fact that would justify a review in the variables describing the constructs (Garcia, 1995; Hair et al., 2009).

According to the factor loading results of the 'Support' construct, all loads were $\geq 0.644$, and it indicates a strong grip in the variables of the construct. The most representative variable assisting the construct was VCA2 (0.877) [The top management provides adequate resources to promote the SPC]. Based on the opinion of respondents, the best way to represent the support given to the senior management through the SPC activities provides the adequate resources for the program. The other variables are also representative of the 'Support' construct but they are less intense.

In relation to the construct 'Training', all variables that made up this construct presented factor loading $\geq 0.661$ and it indicates that all variables explaining this construct are significant. The variable presenting the greatest factorial load was the VT1 (0.840) [Basic training in SPC was given to workers involved in manufacture]. 


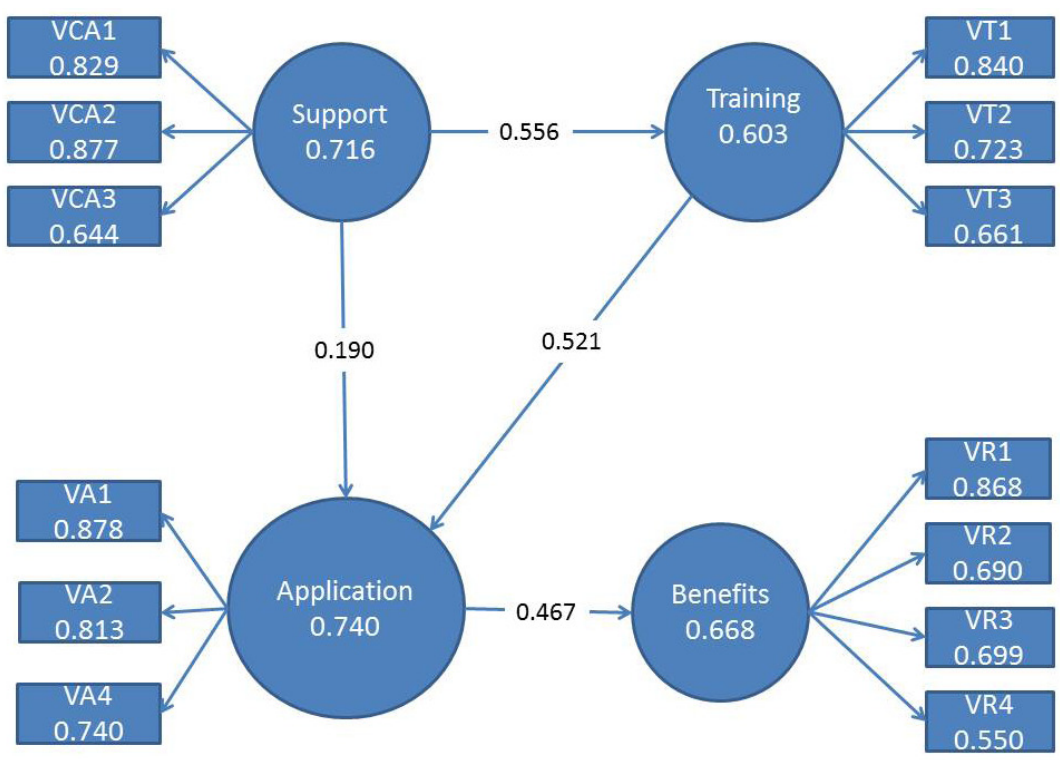

Figure 2. Patch diagram.

According to the respondents, the training offered at the operational level is the most representative variable of this construct.

As for the 'Application' construct, all variables composing this construct presented factor loadings $\geq 0.740$. Such result indicates that all variables explaining this construct are significant. The variable with the greatest factorial load was the VA1 (0.878) [appropriate control charts are used to monitor process stability]. According to the respondents, the application of control charts to monitor the production process is considered the most significant variable of this construct.

Regarding the construct 'Benefit', all variables composing this construct presented factor loading $\geq 0.550$. Such result indicates that all variables explaining this construct are significant. The variable with the greatest load factor was VR1 (0.868) [SPC substantially increases customer satisfaction]. According to the respondents, the increased customer satisfaction can be considered the most prominent benefit obtained from causal relations expressed through the model.

\subsection{Analyzing the relationships between constructs and the validation of the hypotheses}

H1:Top management commitment positively affects the training and education of SPC

The first hypothesis proposed by the conceptual model investigates the relationship between Support and Training. A factor loading 0.566 was observed. Such value indicates that one cannot reject the influence of the construct 'Support' on Training development. Companies where the senior management is leading efforts for quality programs assure the structure and resources to promote proper training structure, and staff training in practical situations concerning the company's daily routine and the recycling of learned concepts. Accordingly, the variables belonging to the construct 'Support' are crucial to influence the way the company articulates its Training.

H2:Top management commitment positively affects SPC application and use

The second hypothesis proposed by the conceptual model investigates the relationship between Support and Application. A factor loading 0.190 was observed. Such value indicates that it may reject the influence of the construct 'Support' on senior management in SPC Application. Therefore, the variables belonging to the construct 'Support' did not directly influence SPC application.

H3: The statistical training increases the technical understanding about SPC, and consequently, it positively affects SPC application and use 
The third hypothesis proposed by the conceptual model investigates the relationship between Training and Application. A factor loading 0.521 was observed. Such value indicates that it is not possible to refuse the direct influence of the construct 'Training' and of its interactions with the 'Application'.

When training courses and SPC improvement application tools are regularly held and directed to workers related to production and the acquired knowledge about SPC is applied immediately after training, this training articulation directly influences the proper selection of control charts. It is an observance of the Statistical assumptions identified and allows removing special variation causes. Therefore, it is conclusive that the practices represented by the construct 'Training' directly influenced the way SPC was applied in the organization.

H4: The correct application of control charts positively affects the benefits generated by the program

The fourth hypothesis proposed by the conceptual model investigates the relationship between Application and Benefits. A factor loading 0.467 was observed. Such value indicated that it is not possible rejecting the influence of the construct 'Application' and of its interactions with the 'Benefits'.

Therefore, the observation of the statistical assumptions associated with the use of appropriate control charts and especially the performance of variation causes are crucial to the development of the skills of people involved with the SPC to solve problems, reduce process variability and, mainly, to increase customers' satisfaction. It was observed in the field that companies using proper SPC tools as a mechanism to solve costumer's problems have great influence on customer's satisfaction. The benefits from SPC implementation are partly attributed to its proper application.

However, given the fragility of such relationship, because factor loading $<0.5$, it is appropriate to infer that there are other factors and variables not prescribed by this model and also influenced in getting benefits. Future studies seeking to analyze the causal relationships between CSF and benefits using other variables may complete the results found in the present study. Table 5 summarizes the validation of the research hypotheses.

Table 5. Summarizes the validation of research hypotheses.

\begin{tabular}{cll}
\hline & \multicolumn{1}{c}{ Research Hypotheses } & \multicolumn{1}{c}{ Validation } \\
\hline $\mathrm{H}_{1}$ & $\begin{array}{l}\text { Top management commitment positively affects the training and } \\
\text { education of SPC }\end{array}$ & $\begin{array}{l}\text { There is no evidence to refute this hypothesis } \\
\mathrm{H}_{2}\end{array} \quad \begin{array}{l}\text { Top management commitment positively affects SPC application } \\
\text { and use }\end{array}$ \\
\hline $\mathrm{H}_{3}$ & $\begin{array}{l}\text { The statistical training increases the technical understanding about } \\
\text { SPC, and consequently, it positively affects SPC application and use }\end{array}$ & There is evidence to refute this hypothesis \\
$\mathrm{H}_{4}$ & $\begin{array}{l}\text { The correct application of control charts positively affects the } \\
\text { benefits generated by the program }\end{array}$ & There is no evidence to refute this hypothesis \\
\hline
\end{tabular}

\section{Research limitations}

The research limitations are related to the difficulty of having access to the entire population and of getting answers, since the participation of companies/respondents was voluntary. The lack of companies' adherence to conduct the studies has impacted on the amount and quality of valid data (Forza, 2002). Such issue limited the sample size, which just comprised 43 respondents. However, although the small sample size, was not found significant violations in the statistical assumptions (multivariate normality and multicollinearity) a robust method (PLS) was used to minimize possible estimation errors; such method is suitable to small samples and exploratory models.

Despite the choice for the method, the small sample is a limitation that may lead to false positives and to difficulty to generalize the results in the study. Small samples are common in exploratory models and in studies about strategic management, creating difficulties for the results generalizations (Hair et al., 2012). Studies related to strategic management have much smaller sample sizes in comparison to other field studies, although PLS-SEM can be used in smaller sample sizes, there are problems associated (Hair et al., 2012). The more heterogeneous the population, the larger the required sample size necessary to adequately reflect the population and to obtain accurate estimates. Smaller sample sizes can generate larger sampling errors, which become more severe with heterogeneous populations. The auto-parts industries have specific characteristics that can interfere on the application of control charts such as production volume and variety. However, there was no outlier in the survey sample. Another problem concerns the effect of the bias generated by small sample sizes that accentuated non-normal data (Hair et al., 2012); however it was not the case of the present data. 
The study limitations do not allow generalizations. However, since it is an exploratory study, it provides an initial view of the relations between CSF and the studied constructs. Future researches can replicate the study in larger samples, in other sectors and even increase the number of critical factors and involved constructs.

\section{Conclusions}

The support to lead quality improvement efforts that provide adequate resources to promote program activities and structure for the SPC directly influenced the way organizations articulate their training. It also enabled offering basic training to SPC workers involved in manufacture, as well as the application of the knowledge acquired immediately after the training to practical situations and the conduction of knowledge enhancement as appropriate.

In turn, such proper training reflects on the best observation of the statistical assumptions involved with the control chart using graphics suitable to monitor process stability. These graphs also allow identifying and minimizing the variance effect in the process. Managers achieve a substantial increase in customer's satisfaction, an analytical improvement in skills and in solving problems of those involved in the SPC as a direct consequence of the reduced variability. Additionally, the positive impacts on reducing defects and productivity gains are also reported as benefits.

It is possible saying that the aim of the present article to explain the causal relationships between CSF and its effects on SPC deployment in Brazilian auto-parts companies was achieved, since the study established the causal relationships herein suggested. The results indicated that the senior management support considerably affected the way companies develop their training. In turn, these trainings affect the way companies apply techniques, and hence this will reflect on the benefits seen with the implementation of the program. It was also observed that the managerial and technical aspects are closely connected to each other and are represented through the ratio between the top management and training support, and the technical aspects observed in the application directly affect the benefits from the program.

\section{References}

Ahmed, A. F. T. A. B., Khan, 1., \& Ghosh, M. K. (2012). SPC implementation in pharmaceutical industry for material flow management. Interscience Management Review, 2(3), 57-60.

Antony, J., \& Taner, T. (2003). A conceptual framework for the effective implementation of statistical process control. Business Process Management Journal, 9(4), 473-489. http://dx.doi. org/10.1108/14637150310484526.

Antony, J., Balbontin, A., \& Taner, T. (2000). Key ingredients for the effective implementation of statistical process control. International Journal of Productivity and Performance Management, 49(6), 242-247. http://dx.doi.org/10.1108/00438020010343417.

Basilevsky, A. T. (1994). Statistical factor analysis and related methods: theory and applications. New York: John Wiley \& Sons.

Bhote, K. R. (1987). SPC made easier, simpler, more statistically powerful. Target, 3(3), 12-20.

Biolchini, J. C. A., Mian, P. G., Natali, A. C. C., Conte, T. U., \& Travassos, G. H. (2007). Scientific research ontology to support systematic review in software engineering. Advanced Engineering Informatics, 21(2), 133-151. http://dx.doi.org/10.1016/j. aei.2006.11.006.

Brereton, P., Kitchenham, B. A., Budgen, D., Turner, M., \& Khalil, M. (2007). Lessons from applying the systematic literature review process within the software engineering domain. Journal of Systems and Software, 80(4), 571-583. http://dx.doi. org/10.1016/j.jss.2006.07.009.

Burr, 1. W. (1976). Statistical quality control methods (16th ed.). New York: CRC Press.

Caulcutt, R. (1996). Statistical process control (SPC). Assembly Automation, 16(4), 10-14. http://dx.doi.org/10.1108/01445159610150972.

Chen, S. H., Yang, C. C., Lin, W. T., \& Yeh, T. M. (2008). Performance evaluation for introducing statistical process control to the liquid crystal display industry. International Journal of Production Economics, 111(1), 80-92. http://dx.doi.org/10.1016/j. ijpe.2006.12.055.

Cochran, W. G. (1977). Sampling techniques. New York: John Wiley and Sons.

Does, R. J. M. M., Trip, A., \& Schippers, W. A. J. (1997). A framework for implementation of statistical process control. International Journal of Quality Science, 2(3), 181-198. http:// dx.doi.org/10.1108/13598539710170821.

Elg, M., Olsson, J., \& Dahlgaard, J. (2008). Implementing statistical process control: an organizational perspective. International Journal of Quality \& Reliability Management, 25(6), 545-560. http://dx.doi.org/10.1108/02656710810881872.

Forza, C. (2002). Survey research in operations management: a process-based perspective. International Journal of Operations \& Production Management, 22(2), 152-194. http://dx.doi. org/10.1108/01443570210414310.

Fryer, K. J., Antony, J., \& Douglas, A. (2007). Critical success factors of continuous improvement in the public sector. The TQM Magazine, 9(5), 497-517. http://dx.doi.org/10.1108/09544780710817900.

Garcia, J. G. (1995). Análise de la información mercadológica através de la estatística multivariante. Ciudad de Mexico: Alambra Mexicana.

Gordon, M. E., Philpot, J. W., Bounds, G. M., \& Long, W. S. (1994). Factors associated with the success of the implementation of statistical process control. The Journal of High Technology Management Research, 5(1), 101-121. http://dx.doi. org/10.1016/1047-8310(94)90016-7.

Grigg, N., \& Walls, L. (2007a). Developing statistical thinking for performance improvement in the food industry. International Journal of Quality \& Reliability Management, 24(4), 347-369. http://dx.doi.org/10.1108/02656710710740536.

Grigg, N., \& Walls, L. (2007b). The role of control charts in promoting organisational learning: New perspectives from a 
food industry study. The TQM Magazine, 19(1), 37-49. http:// dx.doi.org/10.1108/09544780710720826.

Hair, J. F., Black, W. C., Babin, B. J., Anderson, R. E., \& Tatham, R. L. (2009). Análise multivariada de dados (6. ed.). Porto Alegre: Bookman Editora.

Hair, J. F., Hult, T. M., Ringle, C. M., \& Sarstedt, M. A. (2014). Primer on Partial Least Squares Structural Equation Modeling (PLS-SEM). Los Angeles: SAGE.

Hair, J. F., Ringle, C. M., \& Sarstedt, M. (2011). PLS-SEM: indeed a silver bullet. Journal of Marketing Theory and Practice, 19(2), 139-152. http://dx.doi.org/10.2753/MTP1069-6679190202.

Hair, J. F., Sarstedt, M., Pieper, T. M., \& Ringle, C. M. (2012). The use of partial least squares structural equation modeling in strategic management research: a review of past practices and recommendations for future applications. Long Range Planning, 45(5), 320-340. http://dx.doi.org/10.1016/j.lrp.2012.09.008.

Hayes, G. E., \& Romig, H. G. (1977). Modern quality control. Los Angeles: Bruce.

Hoerl, R. W., \& Snee, R. D. (2010). Closing the gap. Quality Progress, 43(5), 52-53.

Jobson, J. (1992). Applied multivariate data analysis: categorical and multivariate methods. New York: Springer Science \& Business Media.

Judi, H. M., Jenal, R., \& Genasan, D. (2009). Some experiences of quality control implementation in Malaysian companies. European Journal of Scientific Research, 271), 34-45.

Laohavichien, T., Fredendall, L. D., \& Cantrell, R. S. (2011). Leadership and quality management practices in Thailand. International Journal of Operations \& Production Management, 31(10), 1048-1070. http://dx.doi.org/10.1108/01443571111172426.

Lee, H. J. (2004). The role of competence-based trust and organizational identification in continuous improvement. Journal of Managerial Psychology, 19(6), 623-639. http:// dx.doi.org/10.1108/02683940410551525.

Lim, S. A. H., \& Antony, J. (2013). A conceptual readiness framework for statistical process control (SPC) deployment. In Proceedimgs of the Industrial Engineering and Engineering Management (IEEM), 2013 IEEE International Conference (pp. 300-304), Bangkok. http://dx.doi.org/10.1109/ieem.2013.6962422

Lim, S. A. H., Antony, J., \& Albliwi, S. (2014). Statistical Process Control (SPC) in the food industry: a systematic review and future research agenda. Trends in Food Science \& Technology, 372), 137-151. http://dx.doi.org/10.1016/j.tifs.2014.03.010.

Mahanti, R., \& Evans, J. R. (2012). Critical success factors for implementing statistical process control in the software industry. Benchmarking: An International Journal, 19(3), 374-394. http:// dx.doi.org/10.1108/14635771211244309.

Marin-Garcia, J. A., Val, M. P., \& Martin, T. B. (2008). Longitudinal study of the results of continuous improvement in an industrial company. Team Performance Management, 14(1/2), 56-69. http://dx.doi.org/10.1108/13527590810860203.

Mason, B., \& Antony, J. (2000). Statistical process control: an essential ingredient for improving service and manufacuring quality. Managing Service Quality: An International Journal, 10(4), 233-238. http://dx.doi.org/10.1108/09604520010341618.
Montgomery, D. C. (2010). A modern framework for achieving enterprise excellence. International Journal of Lean Six Sigma, 1(1), 56-65. http://dx.doi.org/10.1108/20401461011033167.

Montgomery, D. C. (2014). Introdução ao controle estatístico da qualidade (4. ed.) Rio de Janeiro: Grupo Gen-LTC.

Oakland, J. S. (2008). Statistical process control (5th ed.). Oxford: Routledge.

Phyanthamilkumaran, S. Z., \& Fernando, Y. (2008). The role of cultural change in the relationship between critical factors with the success of Statistical Process Control (SPC) projects. Proceedings of Annual London Conference on Money, Economy and Management, 3(4), 1-11.

Putri, T. N., \& Yusof, S. R. M. (2008). Critical success factors for implementing quality engineering (QE) in Malaysian's and Indonesian's automotive industries: a proposed model. International Journal of Automotive Industry and Management, (2), 1-15.

Rantamäki, J., Tiainen, E. L., \& Kässi, T. (2013). A case of implementing SPC in a pulp mill. International Journal of Lean Six Sigma, 4(3), 321-337. http://dx.doi.org/10.1108/IJLSS-05-2013-0029.

Rohani, J. M., Yusof, S. M., \& Mohamad, I. (2009). The relationship between statistical process control critical success factors and performance: A structural equation modeling approach. In 2009 IEEE International Conference on Industrial Engineering and Engineering Management (pp. 1352-1356), Hong Kong. http://dx.doi.org/10.1109/ieem.2009.5373033

Rohani, J. M., Yusof, S. R. M., \& Mohamad, I. (2010). The development of a survey instrument for measuring a relationship between statistical process control success factors and performance. Jurnal Mekanikal, (30), 1-16. http://dx.doi.org/10.1109/ ieem.2009.5373033.

Rungasamy, S., Antony, J., \& Ghosh, S. (2002). Critical success factors for SPC implementation in UK small and medium enterprises: some key findings from a survey. The TQM Magazine, 14(4), 217-224. http://dx.doi.org/10.1108/09544780210429825.

Rungtusanatham, M., Anderson, J. C., \& Dooley, K. J. (1999). Towards measuring the "SPC implementation/practice" construct: Some evidence of measurement quality. International Journal of Quality \& Reliability Management, 16(4), 301-329. http:// dx.doi.org/10.1108/02656719910239938.

Sharma, R., \& Kharub, M. (2014). Attaining competitive positioning through SPC: an experimental investigation from SME. Measuring Business Excellence, 18(4), 86-103. http://dx.doi.org/10.1108/ MBE-10-2013-0050.

Tranfield, D., Denyer, D., \& Smart, P. (2003). Towards a methodology for developing evidence-informed management knowledge by means of systematic review. British Journal of Management, 14(3), 207-222. http://dx.doi.org/10.1111/1467-8551.00375.

Woodall, W. H. (2000). Controversies and contradictions in statistical process control. Journal of Quality Technology, 32(4), 341-350.

Woodall, W. H., \& Montgomery, D. C. (1999). Research issues and ideas in statistical process control. Journal of Quality Technology, 31(4), 376-387.

Xie, M., \& Goh, T. N. (1999). Statistical techniques for quality. The TQM Magazine, 11(4), 238-242. http://dx.doi. org/10.1108/09544789910272913.

Yamamoto, Y., \& Bellgran, M. (2013). Four types of manufacturing process innovation and their managerial concerns. Procedia CIRP, 7, 479-484. http://dx.doi.org/10.1016/j.procir.2013.06.019. 